\title{
The Treatment of Movement Disorders by Deep Brain Stimulation
}

\author{
Hong Yu and Joseph S. Neimat \\ Department of Neurological Surgery, Vanderbilt University, Nashville, Tennessee 37232
}

\begin{abstract}
Summary: It has been understood, for some time, that modulation of deep brain nuclei within the basal ganglia and thalamus can have a therapeutic effect in patients with movement disorders. Because of its reversibility and adjustability, deep brain stimulation (DBS) has largely come to replace traditional ablation procedures. The clinical effects of DBS vary, depending both on the target being stimulated and on the parameters of stimulation. Both aspects are currently the subject of substantial research and discovery. The most common targets for DBS
\end{abstract}

treatment include the subthalamic nucleus for the treatment of advanced Parkinson's disease, the ventral intermediate nucleus of the thalamus for the treatment of medically refractory essential tremor, and the globus pallidus interna for the treatment of both cervical and generalized dystonias and Parkinson's disease. We review the current indications, targets, outcomes, and general procedure of DBS for essential tremor, Parkinson's disease, and dystonia. Key Words: Movement disorders, Parkinson's disease, essential tremor, dystonia, deep brain stimulation, DBS.

\section{INTRODUCTION}

Deep brain stimulation (DBS) is a technique whereby electrical current is applied to various parts of the brain via implanted electrodes. DBS took its roots from the ablative procedures that used to be the mainstay surgical treatment for movement disorders. During pallidotomies and thalamotomies, it was observed that high-frequency stimulation at the targets of these ablative surgeries produced clinical effects similar to the ablation itself. ${ }^{1,2}$ In contrast to the permanent effects of ablation, adverse effects produced by stimulation are generally reversible once the stimulation has been turned off. DBS was thus felt to offer a safer and more attractive alternative.

The specific symptoms treated by DBS depend on the location of the implant. Thalamic DBS received U.S. Food and Drug Administration (FDA) approval for the treatment of Parkinson's disease (PD) tremor and essential tremor in 1997. Shortly thereafter, in 2002, DBS of the subthalamic nucleus (STN) and the globus pallidus pars interna (GPi) was approved for use in patients with PD. In 2003, DBS of the GPi and STN for dystonia received a Humanitarian Device exemption from the

Address correspondence and reprint requests to: Joseph S. Neimat, M.D., Assistant Professor, Vanderbilt University, Department of Neurological Surgery, MCN T-4224, Nashville, TN 37232. E-mail: jneimat@gmail.com.
FDA. Even though a complete understanding of the mechanism of DBS is lacking, a growing body of literature supports the efficacy of DBS for the treatment of movement disorders. In this article, we review the application of DBS for the treatment of essential tremor, PD, and dystonia.

\section{ESSENTIAL TREMOR}

Essential tremor (ET) is one of the most common movement disorders, affecting up to $5 \%$ of people over the age of $60 . .^{3}$ The main clinical manifestations are postural and action tremor involving the upper extremities. A significant number of patients also suffer from axial symptoms such as head and voice tremor. It is estimated that $50 \%$ of ET patients do not respond to medical treatment. ${ }^{4}$ For some of those patients, the tremor is debilitating enough to warrant surgical treatment.

The ventral intermediate nucleus (VIM) is the portion of the motor thalamus that contains the cerebellar receiving area. ${ }^{5}$ The VIM projects mainly to the motor cortex and is the primary surgical target for the treatment of tremor. ${ }^{6}$ Microelectrode recordings (MERs) from the VIM reveal many cells that fire at the same frequency as the patient's tremor. ${ }^{7,8}$ Lesioning in the area of tremor cells leads to long-term relief of tremor. ${ }^{9,10}$ This is the basis for using ablative thalamotomy in the treatment of 
tremor. During intraoperative physiologic mapping for thalamotomy, it was also noted that high-frequency stimulation $(>100 \mathrm{~Hz})$ of the VIM had similar tremor-reducing effects. ${ }^{1,2}$ Although the exact pathophysiology of tremor is unknown, it is hypothesized that tremor cells are central oscillators and that constant, high-frequency stimulation may block or override the abnormal oscillatory signals produced by these tremor cells. ${ }^{7,11}$

The beneficial effect of VIM DBS on ET has been well documented. Several case series have demonstrated that $\sim 80 \%$ of patients experience significant overall tremor relief, with $83 \%$ average reduction in formal tremor scores, such as the Fahn-Tolosa-Marin tremor score. ${ }^{12-16}$ Significant tremor relief lasting up to 6 years has been demonstrated more recently in double-blind testing with stimulation on and off in implanted patients. ${ }^{17}$ VIM DBS can also improve axial tremors, such as an average of $85 \%$ reduction in head tremor and $83 \%$ reduction in voice tremor. ${ }^{18,19}$ Within those series, when bilaterally implanted patients were stratified apart from those with unilateral implants, bilateral VIM DBS appears significantly more effective in reducing midline symptoms, such as head tremor. ${ }^{19,20}$

The differential effect of bilateral versus unilateral stimulation on voice tremor is less clear. ${ }^{19,21}$ Although long-term studies found that most patients enjoyed persistent tremor control from their VIM DBS for up to 6.5 years, a subset of patients suffered a decline of the initial therapeutic effect over time. ${ }^{15,22}$ In one series, this phenomenon was noted in $18.5 \%$ of patients with $>6$ months of follow-up. ${ }^{23}$ Another series reported a $12 \%$ reduction in the degree of tremor improvement at 6.5 years, compared with 1 year, postoperatively. ${ }^{22}$ The exact reason for this decline in efficacy is unclear, but it may be due to tolerance or to disease progression.

The results of VIM DBS for other tremor syndromes, such as multiple sclerosis or post-stroke-related tremor, have been mixed. ${ }^{24}$ The pathophysiology of secondary tremor syndromes may differ from that of essential tremor. These secondary tremor syndromes in general have a greater proximal component, which has traditionally been harder to treat with thalamotomy. ${ }^{6}$ Primate studies reveal that that proximal muscle groups have a larger somatotopic area of representation in the VIM than distal groups, which may contribute to the variance in the response to lesioning. ${ }^{25}$ Some authors have proposed using differential targeting for the different tremor types; for example, the anterior-superior VIM may be more effective for proximal tremor control, whereas the inferior VIM may more effective for distal tremor control. ${ }^{26}$ Others have achieved control of complex tremor syndromes through the use of additional electrodes implanted just anteriomedial to the original VIM lead, thereby spreading the stimulation area into other tremor pathways. $^{27}$
Bilateral DBS has been associated with less morbidity than bilateral thalamotomy. ${ }^{28-30}$ Unlike thalamotomy, bilateral VIM DBS has not been associated with as high a risk of cognitive problems. ${ }^{29,30}$ Stimulation-induced adverse effects include worsening of dysarthria, paresthesia, gait disorder, and pain. All of these are reversed when the stimulation is turned off and can be minimized with stimulation adjustments. ${ }^{23,31,32}$ Paresthesia is, by far, the most common stimulation-induced adverse effect, with reported rates up to $79 \% .^{31,32}$ Just posterior to the motor thalamus, in the nucleus ventralis caudalis (VC), lies the lemniscal receiving area of the sensory thalamus. Thus, paresthesia side effects are likely due to the spillover of stimulation field into the sensory thalamus. ${ }^{6}$ Dysarthria is more commonly caused by bilateral as opposed to unilateral VIM DBS and can also be seen in patients with unilateral DBS who had a previous contralateral thalamotomy. ${ }^{19,23,24}$ Unlike the case with bilateral thalamotomy, which is associated with nearly $30 \%$ risk of permanent speech and cognitive deficits, stimulation-induced dysarthria is generally reversible once the DBS unit is off. ${ }^{33}$

\section{PARKINSON'S DISEASE}

Parkinson's disease is the second most common neurodegenerative disease, affecting 1-3\% of all people over the age of $65 . .^{34,35}$ It is estimated that $>4$ million people worldwide suffer from PD. ${ }^{36}$ The cardinal signs of PD include tremor, rigidity, and bradykinesia. Levodopa is the main medical therapy for PD. Unfortunately, as the disease progresses, the effectiveness of the medication often becomes less lasting. Patients develop on-medication and off-medication periods that change quickly and are difficult to control. It is estimated that $28 \%$ of PD patients suffer from debilitating motor symptoms (akinesia, rigidity, tremor) despite optimal medical therapy. ${ }^{37}$ The high doses of levodopa required to alleviate their rigidity and bradykinesia can also cause debilitating dyskinesia.

The following summarizes the patient selection criteria for DBS in treating PD, as detailed in the report from the Consensus on Deep Brain Stimulation for Parkinson's Disease. ${ }^{38}$ Preoperative levodopa responsiveness has been shown to be the best predictor of DBS response. ${ }^{39,40}$ Thus, a good DBS candidate should have symptomatic response to levodopa as reflected by a $>25-50 \%$ reduction in Unified PD Rating Scale (UPDRS) part III scores during a levodopa challenge (which is a sufficient dose of levodopa to reproduce the patient's best on-medication response). The ideal patient should also be severely disabled from the parkinsonian motor symptoms in the off-medication state (UPDRS motor score $>30 / 108$ ) but independent in the on-medication state (UPDRS motor score <30/108). 
Generally, the patient should be symptomatic for 5 years, to allow time to rule out the presence of Parkinson-plus syndromes, such as progressive supranuclear palsy or multiple system atrophy. DBS is not recommended for patients with Parkinson-plus syndromes. To objectively track the efficacy of DBS, most centers perform preoperative and serial postoperative clinical evaluations using UPDRS scores, as well as quality of life and neuropsychological scores.

Contraindications to DBS include dementia, extensive brain atrophy, comorbid conditions that preclude safe surgery, and noncompliance.

The pathophysiology of PD is the subject of extensive investigation. From animal models of PD, researchers developed the traditional model of basal ganglia motor pathways, which consist of direct and indirect pathways involving the globus pallidus pars interna (GPi), thalamus, and subthalamic nucleus (STN). ${ }^{41}$ It was thought that degeneration of the substantia nigra pars compacta leads to a depletion of dopaminergic output, thereby altering the balance in this cortico-basal gangliathalamocortical circuit. ${ }^{42}$ Later studies have revealed that this traditional model may be too simplistic, in that many more nuclei have been linked to the basal ganglia motor pathways $^{43,44}$ (FIG. 1). Over the years, many targets have been used for the treatment of PD.

\section{Ventral intermediate nucleus}

The first reports of DBS for the treatment of PD used thalamic stimulation. In a series of 80 PD patients treated with either unilateral or bilateral VIM DBS, Benabid et al. ${ }^{23}$ found that $88 \%$ of the patients had complete or near-complete tremor relief on the Fahn-Tolosa-Marin scale at 6 months to 8 years, postoperatively. The effects of VIM DBS on the other symptoms of PD, however, such as rigidity, bradykinesia, or drug-induced dyskinesias, were either short lasting or nonexistent. Currently, the role of VIM DBS in PD is limited to patients with tremor-predominant symptoms.

\section{Subthalamic nucleus}

The STN is a small nucleus located in the upper portion of the midbrain. Through extensive animal studies, the STN has been shown to play an integral role in the cortical-basal ganglia-thalamocortical pathways. According to the traditional basal ganglia model of PD, the loss of dopamine results in increased STN activity, thereby stimulating the GPi and substantia nigra pars reticulata $(\mathrm{SNr})$. The net result is overinhibition of the motor thalamus from the pallidothalamic and nigrothalamic projections. ${ }^{6,45}$

A hyperactive STN with abnormal bursting activity is confirmed in both animal PD models and human PD patients. ${ }^{46-48}$ Primate studies have also revealed the presence of tremor cells in the STN, similar to those found in the VIM. ${ }^{47}$ Modulation of this nucleus has the theoretical advantage that upstream intervention should more completely suppress both indirect and direct pathways. Lesioning of the STN in primate models of PD has been shown to reduce contralateral tremor, rigidity, and akinesia $^{49,50}$; however, clinicians were reluctant to use STN ablation for the treatment of PD, because of the association between hemiballism and infarctions in the region of STN in non-PD patients. ${ }^{51}$ The reversibility and adjustability of DBS have encouraged investigators to attempt STN DBS. The safety and efficacy of STN DBS were first demonstrated in nonhuman primates, and subsequently in humans. ${ }^{52}$

The clinical efficacy of STN DBS in the reduction PD symptoms has been reported by numerous investigators and been validated in prospective, randomized trials. Although there is generally no improvement in on-medication UPDRS motor subscores, the scores in the offmedication state improve by an average of $52 \%$ over an average of 15 months of DBS therapy. ${ }^{53}$ A $50-60 \%$ reduction in postoperative levodopa dose leads indirectly to improvement in levodopa-induced dyskinesia. ${ }^{53,54}$ On-medication dyskinesias are reduced by $94 \%$ after 12 months of STN DBS. ${ }^{54}$

Long-term follow-up results show sustained improvement in tremor, rigidity, akinesia in the off-medication state, and reduction in dopaminergic medication requirement at 5 years after implant. ${ }^{55,56}$ Initial improvements in gait, however, are not sustained at 5 years. A recent European multicenter study of 159 patients randomized to receive STN DBS or best medical therapy demonstrated that patients receiving DBS surgery had significant improvements in quality of life measures, as well as in the amount of time in the 'on' condition each day and in 'off' UPDRS motor subscores at 6-month follow-up. ${ }^{57}$ In addition, Schüpbach et al. ${ }^{58}$ recently demonstrated that STN DBS was effective in treating early PD patients with disease of 5-10 year duration and Hoehn and Yahr stage of $\leq 3$.

Quality of life is significantly improved after STN DBS compared to medical therapy. ${ }^{57,58}$ This has been shown over the long term in prospective open-label trials $^{55,56}$; however, more recent data suggest that, although STN DBS improves motor components of PD in both young and old patients, there may be a lesser improvement in quality of life in patients older than $65 .{ }^{59}$

Stimulation-induced adverse motor symptoms from STN DBS can often be reversed by reprogramming. Early case series reported hemiballism induced by stimulation at high voltages. ${ }^{60}$ A recent systematic review found that $19 \%$ of STN DBS patients have reversible motor side effects such as dyskinesia, paresthesia, and dysphonia. ${ }^{54}$ Speech difficulties appeared to be more frequent in patients with left STN stimulation. ${ }^{61}$

Studies have suggested that STN DBS can be associated with cognitive and affective side effects. In a pooled analysis of 82 case series, cognitive impairments affect- 


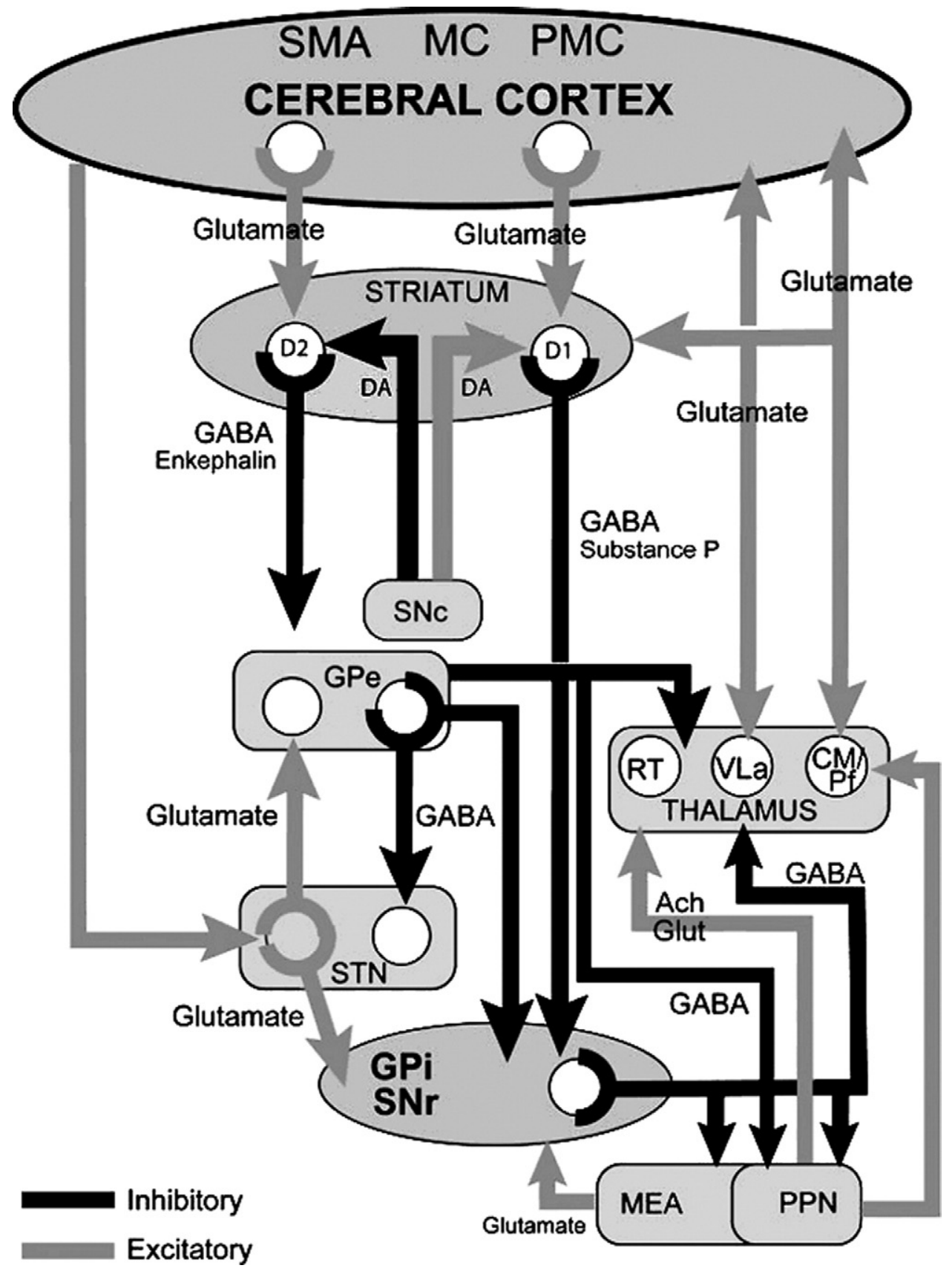

FIG. 1. Diagram illustrating connectivity among nuclei of the basal ganglia. The putative direct and indirect pathways are shown, as are known additional connections between STN and GPe, and between midbrain nuclei and nuclei in the basal ganglia and thalamus. ${ }^{45}$ Ach $=$ acetylcholine; $\mathrm{CM} / \mathrm{Pf}=$ thalamic centromedian/nucleus parafascicularis; $\mathrm{D} 1$ and $\mathrm{D} 2=$ dopamine receptors; $\mathrm{DA}=\mathrm{dopamine}$; GABA $=\gamma$-aminobutyric acid; Glut = glutamate; $\mathrm{GPe}=$ globus pallidus externus; $\mathrm{GPi}=$ globus pallidus internus; $\mathrm{MC}=$ motor cortex; $\mathrm{MEA}$ $=$ midbrain extrapyramidal area; $\mathrm{PMC}=$ premotor cortex; PPN = pedunculopontine nucleus; $\mathrm{RT}=$ nucleus reticularis thalami; $\mathrm{SMA}=$ supplementary motor area; $\mathrm{SNc}=$ substantia nigra pars compacta; $\mathrm{SNr}=$ substantia nigra pars reticulata; $\mathrm{STN}=$ subthalamic nucleus; $\mathrm{VLa}=$ ventral lateral anterior nucleus [of thalamus].

ing memory, executive function, attention, and mental speed were found in up to $41 \%$ of STN DBS patients. ${ }^{62}$ The analyzed series did not uniformly control for potential predisposing factors, however, such as age, preoperative psychiatric condition, and cognitive baseline. Depression and mania have also been noted after STN DBS. ${ }^{63,64}$ Perhaps most concerning is a cohort study that observed an attempted suicide rate of $4.3 \%$ in a series of 140 patients who had undergone DBS. ${ }^{65}$ In that study, however, all but one of the patients who committed suicide had preoperative history of major depression, along with prior suicide attempt or ideation. Indeed, preoperative neuropsychological evaluation and adequate treatment for pre-existing psychiatric conditions are part 
of the patient selection process for DBS, as outlined by the Consensus on Deep Brain Stimulation for Parkinson's Disease. ${ }^{38}$

\section{Globus pallidus interna}

The GPi is a major output nucleus of the basal ganglia and a key player in the cortical-basal ganglia-thalamocortical circuit. Similar to the STN and VIM, tremor cells have been found also in the GPi. ${ }^{66} \mathrm{PD}$ is associated with excessive GPi activity, which ultimately results in the overinhibition of the cortical motor areas. ${ }^{67}$ Since the 1960s, pallidotomy has provided PD patients with relief of rigidity, bradykinesia, tremor, and drug-induced dyskinesia. ${ }^{68,69}$ The ideal target for pallidotomy is felt to be the ventral-posteriolateral pallidum, which has now become the target for GPi DBS. ${ }^{70}$

In PD patients, GPi DBS improves tremor, rigidity, and bradykinesia in the off-medication state, as well as drug-induced dyskinesia, resulting in overall improvement in UPDRS motor scores. ${ }^{71-73}$ The most pronounced and long-lasting effect is the reduction in on-medication dyskinesia. ${ }^{74}$ Unlike STN DBS, however, GPi DBS does not lead to reductions in the patient's levodopa requirement. In fact, a long-term study with average follow-up of 32 months found that medication requirement increases after chronic GPi DBS therapy. ${ }^{75}$

Adverse reactions to GPi DBS are few. Stimulationinduced visual phenomena are most common and can be eliminated by programming adjustments. ${ }^{72}$ There have been some reports of cognitive decline in patients after GPi DBS. ${ }^{76}$ The incidence may, however, be less than that after STN DBS. ${ }^{77}$

\section{STN versus GPi DBS for Parkinson's disease}

Several investigators have compared the effectiveness of STN DBS with that of GPi DBS, in hopes of determining the best target for the treatment of PD. In a randomized trial involving 10 patients with either bilateral STN DBS or bilateral GPi DBS, drug-induced dyskinesia improved by $67 \%$ with STN stimulation and by $47 \%$ with GPi stimulation. ${ }^{78}$ GPi DBS produced an additional $40 \%$ improvement in UPDRS part III scores beyond levodopa therapy, whereas STN DBS achieved only an additional $15 \%$ improvement beyond the onmedication state. The STN group also reported a $51 \%$ reduction in medication requirement, but the GPi group showed no significant medication reduction. The beneficial effects of GPi DBS appeared to wane over time.

In another study, in which patients were implanted with both STN and GPi DBS bilaterally, STN stimulation was overall statistically more effective than GPi stimulation, producing $54.5 \%$ as opposed to $43.1 \%$ reduction in UPDRS part III off-medication scores. ${ }^{79}$ In this study, GPi DBS significantly reduced apomorphineinduced dyskinesia, but STN DBS did not. A multicenter nonrandomized study comparing the long-term outcome of STN and GPi DBS found that, at 4-year follow-up, STN DBS led to a $50 \%$ improvement in the UPDRS score, and GPi DBS led to a $39 \%$ improvement. ${ }^{80}$ The STN group showed a 35\% reduction in medication requirement, but also had higher incidence of depression, cognitive decline, speech difficulty, and gait disturbance. Similar results had been reported previously reported from a randomized trial in Oregon. ${ }^{81}$ For many institutions, STN has become the putative target of choice of DBS for the treatment of PD, but the final results of the randomized multicenter trial is pending (www. clinicaltrials.gov NCT00056563). Thus, the issue has not been fully resolved.

\section{DYSTONIA}

Dystonia comprises a heterogeneous group of disorders characterized by sustained muscle contractions that produce repetitive twisting movements and painful abnormal postures. ${ }^{82}$ Dystonia can be generalized (affecting the entire body) or segmental (affecting one or a few parts of the body), and primary (idiopathic) or secondary (caused by known structural lesion or disease). Primary generalized dystonia can be inherited or sporadic. Cervical dystonia is one of the most common forms of primary segmental dystonia; it presents with sustained cervical muscle contraction causing abnormal neck twisting. ${ }^{83}$

One of the more common inherited forms of primary generalized dystonia is the DYT1 variant, which presents in childhood ${ }^{84}$ DYT1 dystonia is caused by a single GAG deletion on the TORIA gene (previously DYT1) found on chromosome 9q34, which encodes an adenosine triphosphatase called torsin $\mathrm{A}^{84,85}$ This form of dystonia has autosomal dominant inheritance, but with $30-40 \%$ penetrance. ${ }^{86}$ Several additional genetic loci contributing to familial dystonia have also been identified and codified with a DYT label, initially termed DYT1-DYT15. ${ }^{87-89}$ As our genetic understanding of the disease expands, better disease classifications and pathophysiologies will be revealed.

Medical treatments for generalized dystonia show mixed results, and many medications are associated with serious adverse effects, such as cognitive dysfunction. ${ }^{90}$ The mainstay of medical therapy for segmental dystonia is selective botulinum toxin A injection. Some $6-14 \%$ of patients do not respond to botulinum toxin, however, and in $3-10 \%$ of the remaining patients it loses clinical efficacy after repeated use. ${ }^{91,92}$ More recently, a recombinant botulinum toxin B (trade name, Myobloc) has been shown to be effective in patients who become resistant to the standard botulinum toxin. ${ }^{93}$

Dystonia patients with symptoms that are medically refractory and causing severe disability have been considered for surgical treatment. Selective peripheral sur- 
gery, such as rhizotomies, denervations, and myotomies, had been primarily used for the treatment of cervical dystonia. ${ }^{94}$ The role of peripheral surgery is limited, however, and it is not indicated for dystonia involving too many muscle groups, because of the risk of postoperative weakness.

Historically, ablation of various deep brain nuclei involved in the cortical-basal ganglia-thalamocortical circuit has been performed in attempts to treat medically refractory generalized dystonia. In the 1950s, the most common targets for ablation in dystonia were in the thalamus. In 1976, Cooper ${ }^{95}$ reported one of the largest series and demonstrated overall improvement in $70 \%$ of dystonia patients who underwent thalamotomy; however, there was much variation in the specific surgical technique and the subnuclei involved. Others found more varied results. ${ }^{94,96-98}$

Most patients with generalized dystonia suffer from bilateral symptoms, but bilateral thalamotomies are associated with a high incidence of speech problems, weakness, and pseudobulbar palsy. ${ }^{96-98}$ Pallidotomies were also performed in dystonia patients, with success rates of 50$80 \% .^{99-101}$ The safety of bilateral GPi DBS and its efficacy in treating dyskinesia in PD patients have raised interest in the use of GPi DBS for the treatment of dystonia.

The pathophysiology of generalized or segmental dystonia is poorly understood, but the GPi appears to play an integral role. Observations made during pallidal surgery reveal an abnormal pattern of firing activity in the globus pallidus of dystonic patients. ${ }^{102}$ MERs demonstrate decreased firing frequencies in the GPi of dystonia patients, compared with those found in PD patients. ${ }^{103}$ Others found a change in the firing pattern of the GPi in dystonia patients, compared with that in PD patients. ${ }^{104}$ Furthermore, there is evidence that GPi firing activity may be inversely related to the severity of dystonia. ${ }^{105}$ Transcranial magnetic stimulation demonstrates decreased motor cortex excitability in dystonia patients, which can be reversed by GPi stimulation. ${ }^{106}$ PET studies indicate higher glucose metabolism in bilateral lentiform nucleus of cervical dystonia patients, regardless of symptom laterality. ${ }^{107}$

Reports on the application of DBS for the treatment of dystonia have primarily focused on GPi DBS, but other targets such as thalamic DBS have been tried, with less reliable results. ${ }^{108}$ Similar to PD treatment, GPi DBS for dystonia targets the posterioventral lateral portion of the GPi. Unilateral DBS can control contralateral limb symptoms, but bilateral DBS is needed to relieve axial symptoms. ${ }^{83}$ For cervical dystonia, bilateral GPi DBS produces $\sim 60 \%$ improvement in the Toronto Western Spasmodic Torticollis Rating Scales (TWSTRS), disability, and pain scores at 20-month follow-up. ${ }^{109}$

Results for primary generalized dystonia are equally positive. One series of seven DYT1 dystonia children treated with GPi DBS reported mean improvement of $90 \%$ in their Burke-Fahn-Marsden dystonia rating scale (BFM) scores and drug reduction at $>1$ year followup. ${ }^{110}$ Another series reported $71 \%$ improvement in postoperative BFM scores in DYT1 dystonia patients and 74\% improvement in non-DYT1 primary generalized dystonia. ${ }^{111}$ A multicenter study using blinded video assessments demonstrated a 55\% average improvement in BFM scores at 1 year after surgery. ${ }^{112}$

A recent randomized multicenter trial, involving 40 patients with primary segmental or generalized dystonia who underwent a 3-month period of blinded real or sham stimulation, found that patients had a $39 \%$ improvement in BFM scores after 3 months of bilateral GPi DBS, compared with only 5\% improvement after 3 months of sham stimulation. ${ }^{113}$ The cross-over group of patients who spent the first 3 months getting sham stimulation and the second 3 months receiving GPi stimulation also showed significant improvement in their BFM scores. There was no significant difference in efficacy between segmental and generalized dystonia patients.

Several authors have reported improvement in blepharospasm after bilateral GPi DBS in patients suffering from Meige's syndrome. ${ }^{114,115}$ A systemic review that stratified outcome based on the etiology of dystonia revealed that DBS is equally effective for DYT1-positive dystonia, DYT1-negative dystonia, tardive dyskinesia, and posttraumatic dystonias, but not effective for dystonia due to birth injury and encephalitis. ${ }^{116}$ Currently, the use of DBS for primary generalized or segmental dystonia is approved by the FDA under provisions of the Humanitarian Device exemption provisions (www.fda. gov HDE\#: H020007), but the use of DBS for treatment of secondary dystonia is off-label.

Unlike the case with PD and ET, the clinical effects of GPi DBS on dystonia appear to be delayed, except for tardive dystonia. Improvement in TWSTRS score in cervical dystonia patients was greater at 1 year postoperatively, compared with score at 3 months. ${ }^{109}$ It has also been noted that dystonia patients undergo more frequent battery replacements, because they generally require stimulation at higher voltage and pulse width than PD or tremor patients. Several reports have explored the use of lower frequency stimulation in treating dystonia. ${ }^{117,118}$ Although frequencies of $<60 \mathrm{~Hz}$ were not efficacious, one group observed that at $80-\mathrm{Hz}$ stimulation was better tolerated and thus provided greater effect in some patients. ${ }^{118}$ Furthermore there have been reports of rebound dystonia after abrupt discontinuation of chronic GPi stimulation. ${ }^{114}$ Other adverse events of GPi DBS for dystonia included stimulation-induced dysarthria and lead infection and dislodgement, but significant cognitive changes have not been noted. ${ }^{113}$ 


\section{SURGICAL PROCEDURE}

Once the target of stimulation has been chosen for the patient, the general surgical procedure for the implantation of the DBS unit follows similar basic steps: 1) image-guided target localization, 2) physiologic target confirmation using MERs and macrostimulation, and 3) implantation of final DBS lead and connection to a programmable internal pulse generator.

Traditionally, image-guided target localization begins with the identification of consistent landmarks, the anterior and posterior commissures ( $\mathrm{AC}$ and $\mathrm{PC}$ ), which form the basis of the Talairach coordinate system. Next, the target of choice is located by measuring known distances relative to $\mathrm{AC}$ and PC. Unfortunately, this indirect method does not account for individual anatomical variability. ${ }^{119}$ Historically, indirect targeting was performed with ventriculography, but this has been replaced in most centers by magnetic resonance imaging (MRI) and computed tomography. MRI provides better resolution to allow direct visualization of some nuclear boundaries, which can help account for some individual variations; however, MRI can have problems with spatial distortion.

Recently, there have been reports of improved anatomic targeting using the red nucleus as a reference. ${ }^{120}$ Other groups have proposed the use of probabilistic statistical atlases, which predict targets based on prior optimal implants. ${ }^{121,122}$ Such methods may enhance the image-guided targeting accuracy by adding a functional aspect to the anatomically based targeting method. After selecting the target point, an entry point is selected such that the trajectory avoids superficial draining veins, sulci, and deep penetrating vessels. (FIG. 2) The use of contrasted MRI for preoperative trajectory planning can assist in avoiding sulci and vessels, which reduces the incidence of hemorrhage complications. ${ }^{123}$

Given the limitations of the current image-guided target localization methods, intraoperative physiologic target confirmation plays a critical role in DBS implantation. The translation of the target coordinates from the image space to the patient's physical space is traditionally performed using a rigid frame, such as the Leksell or Cosman-Roberts-Wells (CRW) frame. More recently, there have been developments of rapid-prototyped miniframes and frameless stereotaxy systems, with reportedly equivalent or better accuracy than traditional frames, as well as improved patient comfort. ${ }^{124,125}$ Intraoperative physiologic localization is generally performed under local anesthesia; however, patients with severe dystonia or pediatric patients may require general anesthesia. In most centers in North America and continental Europe, physiologic mapping consists of MERs, macrostimulation, or both.
MERs were first widely used in the 1960s during thalamotomies. Tungsten or platinum-iridium microelectrodes are used to record single-unit, extracellular action potentials. ${ }^{126}$ MER can detect transitions between gray and white matter based on waveform differences, and different nuclei based on characteristic firing patterns. Identification of kinesthetic neurons, whose firing frequencies are modulated by movement, can help localize motor areas. More refined somatotopic mapping within a particular motor area can be achieved by locating movement-related cells corresponding to movements of specific parts of the body. ${ }^{7}$ Despite the abundant electrophysiologic data provided by MERs, practitioners at some centers debate its necessity and have chosen to rely on macrostimulation with or without local field potentials and impedence measurements via macroelectrodes for physiologic mapping. ${ }^{127}$

Macrostimulation generally provides the final confirmation of the optimal target location. Macrostimulation is performed in the awake patient at clinically relevant stimulation parameters. Clinical efficacy, side effects, and therapeutic window are noted for each test stimulation area. For example, intraoperative stimulation of STN produces relief of contralateral rigidity and bradykinesia, and intraoperative stimulation of the VIM produces cessation of contralateral tremor. Clinical effects of GPi stimulation is often delayed; macrostimulation in these cases is therefore based not on therapeutic response but on the localization of surrounding structures as reference points for proper placement. ${ }^{71}$ The identification of expected side effects is often as important as the observation of clinical efficacy, in that it helps to map the boundaries of the nucleus being targeted. Additionally, when the final position of the DBS electrode is determined, it is important to confirm that the threshold for clinical benefit is substantially less than the threshold for expected adverse effects.

After the desired physiologic target has been determined, the quadripolar DBS electrode is inserted. Currently, there are two FDA-approved models, each consisting of four platinum-iridium contacts, which are 1.5 $\mathrm{mm}$ long. Adjacent contacts are $1.5 \mathrm{~mm}$ apart in the 3387 model and $0.5 \mathrm{~mm}$ apart in the 3389 model (Medtronic, Minneapolis, MN).

Specific stimulation-induced adverse effects have been described earlier for each target. For the most part, all stimulation-induced adverse effects can be abolished by turning the stimulation off, or by changing the active contact or other stimulation parameters. Complications universal to any target include intracranial hemorrhage, lead migration, skin erosion and lead infection. The risk of intracranial hemorrhage has been reported to occur in $\sim 3 \%$ of electrode placements, causing permanent deficits in $0.7 \%$ of cases. ${ }^{54}$ Correlation between target location and hemorrhage risk has been noted, with the highest incidence of hemorrhage found in GPi DBS. ${ }^{128}$ Infection rates have been reported as $3.4 \%$, which is similar to other neurosurgical 

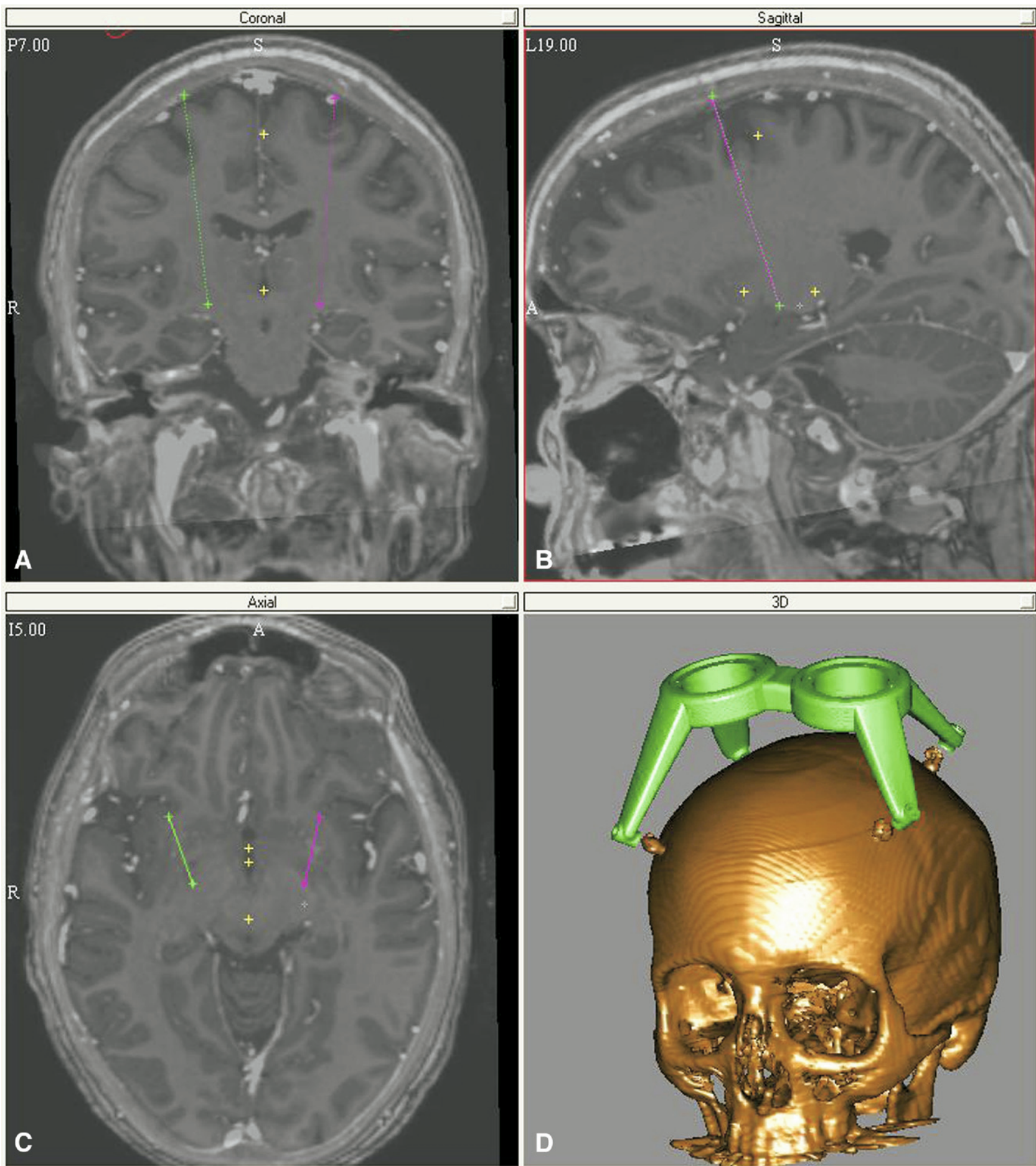

FIG. 2. Trajectory planing for GPI DBS implantation. Demonstrated on the FHC microTargeting WayPoint Planner (FHC, Bowdoinham, ME). A, Coronal. B, Sagittal. C, Axial. D, 3D.

procedures. ${ }^{129}$ Many cases of superficial infections can be treated without hardware removal. ${ }^{54}$

\section{SUMMARY}

DBS has become an important part of the armamentarium for the treatment of movement disorders, such as ET, PD, and dystonia. Prospective, randomized, con- trolled trials demonstrate that DBS is the standard of care for appropriately chosen patients with PD or primary dystonia. The clinical effect of DBS depends on the target of stimulation. Target selection should be based on the symptoms to be treated. As the use of DBS becomes more widespread, we are gaining a better understanding of the efficacy and limitations of the targets currently in 
use. Large-scale, controlled studies will help in determining the optimal target for each symptom. Newer targets are being investigated to capture the symptoms still inadequately controlled by current modalities.

\section{REFERENCES}

1. Hassler R, Riechert T, Mundinger F, Umbach W, Ganglberger JA. Physiological observations in stereotaxic operations in extrapyramidal motor disturbances. Brain 1960;83:337-350.

2. Ohye C, Kubota K, Hongo T, Nagao T, Narabayashi H. Ventrolateral and subventrolateral thalamic stimulation: motor effects. Arch Neurol 1964;11:427-434.

3. Lyons KE, Pahwa R, Comella CL, et al. Benefits and risks of pharmacological treatments for essential tremor. Drug Saf 2003; 26:461-481.

4. Lyons KE, Pahwa R. Deep brain stimulation and essential tremor. J Clin Neurophysiol 2004;21:2-5.

5. Hassler R. Anatomy of the thalamus. In: Schaltenbrand G, Bailey $\mathrm{P}$, editor. Introduction to stereotaxis with an atlas of the human brain. 1st ed. Stuttgart: Thieme, 1959:230-290.

6. Starr PA, Vitek JL, Bakay RA. Deep brain stimulation for movement disorders. Neurosurg Clin North Am 1998;9:381-402.

7. Lenz FA, Kwan HC, Martin RL, Tasker RR, Dostrovsky JO, Lenz YE. Single unit analysis of the human ventral thalamic nuclear group: tremor-related activity in functionally identified cells. Brain 1994;117:531-543.

8. Lenz FA, Tasker RR, Kwan HC, et al. Single unit analysis of the human ventral thalamic nuclear group: correlation of thalamic "tremor cells" with the 3-6 Hz component of parkinsonian tremor. J Neurosci 1988;8:754-764.

9. Hirai T, Miyazaki M, Nakajima H, Shibazaki T, Ohye C. The correlation between tremor characteristics and the predicted volume of effective lesions in stereotaxic nucleus ventralis intermedius thalamotomy. Brain 1983;106:1001-1018.

10. Hubble JP, Busenbark KL, Wilkinson S, Penn RD, Lyons K, Koller WC. Deep brain stimulation for essential tremor. Neurology 1996;46:1150-1153.

11. Dostrovsky JO, Lozano AM. Mechanisms of deep brain stimulation. Mov Disord 2002;17 Suppl 3:S63-S68.

12. Benabid AL, Pollak P, Gervason C, et al. Long-term suppression of tremor by chronic stimulation of the ventral intermediate thalamic nucleus. Lancet 1991;337:403-406.

13. Hubble JP, Busenbark KL, Wilkinson S, et al. Effects of thalamic deep brain stimulation based on tremor type and diagnosis. Mov Disord 1997;12:337-341.

14. Ondo W, Jankovic J, Schwartz K, Almaguer M, Simpson RK. Unilateral thalamic deep brain stimulation for refractory essential tremor and Parkinson's disease tremor. Neurology 1998;51:1063-1069.

15. Koller WC, Lyons KE, Wilkinson SB, Troster AI, Pahwa R. Long-term safety and efficacy of unilateral deep brain stimulation of the thalamus in essential tremor. Mov Disord 2001;16:464468.

16. Fahn S, Tolosa E, Marin C. Clinical rating scale for tremor. In: Jankovic J, Tolosa E, Parkinson's disease and movement disorders, 2nd ed. Baltimore: Williams \& Wilkins, 1993:271-280.

17. Rehncrona S, Johnels B, Widner H, Törnqvist AL, Hariz M, Sydow O. Long-term efficacy of thalamic deep brain stimulation for tremor: double-blind assessments. Mov Disord 2003;18:163-170.

18. Limousin P, Speelman JD, Gielen F, Janssens M. Multicentre European study of thalamic stimulation in parkinsonian and essential tremor. J Neurol Neurosurg Psychiatry 1999;66:289-296.

19. Obwegeser AA, Uitti RJ, Turk MF, Strongosky AJ, Wharen RE. Thalamic stimulation for the treatment of midline tremors in essential tremor patients. Neurology 2000;54:2342-2344.

20. Ondo W, Almaguer M, Jankovic J, Simpson RK. Thalamic deep brain stimulation: comparison between unilateral and bilateral placement. Arch Neurol 2001;58:218-222.

21. Carpenter MA, Pahwa R, Miyawaki KL, Wilkinson SB, Searl JP, Koller WC. Reduction in voice tremor under thalamic stimulation. Neurology 1998;50:796-798.
22. Sydow O, Thobois S, Alesch F, Speelman JD. Multicentre European study of thalamic stimulation in essential tremor: a six year follow up. J Neurol Neurosurg Psychiatry 2003;74:1387-1391.

23. Benabid AL, Pollak P, Gao D, et al. Chronic electrical stimulation of the ventralis intermedius nucleus of the thalamus as a treatment of movement disorders. J Neurosurg 1996;84:203-214.

24. Siegfried J, Lippitz B. Chronic electrical stimulation of the VLVPL complex and of the pallidum in the treatment of movement disorders: personal experience since 1982. Stereotact Funct Neurosurg 1994;62:71-75.

25. Vitek JL, Ashe J, DeLong MR, Alexander GE. Physiologic properties and somatotopic organization of the primate motor thalamus. J Neurophysiol 1994;71:1498-1513.

26. Nguyen JP, Degos JD. Thalamic stimulation and proximal tremor: a specific target in the nucleus ventrointermedius thalami. Arch Neurol 1993;50:498-500.

27. Foote KD, Seignourel P, Fernandez HH, et al. Dual electrode thalamic deep brain stimulation for the treatment of posttraumatic and multiple sclerosis tremor. Neurosurgery 2006;58:ONS-280285; discussion ONS-285-286.

28. Tasker RR. Deep brain stimulation is preferable to thalamotomy for tremor suppression. Surg Neurol 1998;49:145-153; discussion 153-144.

29. Pahwa R, Lyons KE, Wilkinson SB, et al. Comparison of thalamotomy to deep brain stimulation of the thalamus in essential tremor. Mov Disord 2001;16:140-143.

30. Schuurman PR, Bosch DA, Bossuyt PM, et al. A comparison of continuous thalamic stimulation and thalamotomy for suppression of severe tremor. N Engl J Med 2000;342:461-468.

31. Koller W, Pahwa R, Busenbark K, et al. High-frequency unilateral thalamic stimulation in the treatment of essential and parkinsonian tremor. Ann Neurol 1997;42:292-299.

32. Pahwa R, Lyons KL, Wilkinson SB, et al. Bilateral thalamic stimulation for the treatment of essential tremor. Neurology 1999; 53:1447-1450.

33. Jankovic J, Cardoso F, Grossman RG, Hamilton WJ. Outcome after stereotactic thalamotomy for parkinsonian, essential, and other types of tremor. Neurosurgery 1995;37:680-686; discussion 686-687.

34. Twelves D, Perkins KSM, Counsell C. Systematic review of incidence studies of Parkinson's disease. Mov Disord 2003;18: $19-31$.

35. Schoenberg BS. Descriptive epidemiology of Parkinson's disease: disease distribution and hypothesis formulation. Adv Neurol 1987;45:277-283.

36. Dorsey ER, Constantinescu R, Thompson JP, et al. Projected number of people with Parkinson disease in the most populous nations, 2005 through 2030. Neurology 2007;68:384-386.

37. Schrag A, Quinn N. Dyskinesias and motor fluctuations in Parkinson's disease: a community-based study. Brain 2000;123: 2297-2305.

38. Lang AE, Houeto JL, Krack P, et al. Deep brain stimulation: preoperative issues. Mov Disord 2006;21 Suppl 14:S171-S196.

39. Rossi P, Colosimo C, Moro E, Tonali P, Albanese A. Acute challenge with apomorphine and levodopa in parkinsonism. Eur Neurol 2000;43:95-101.

40. Hughes AJ, Lees AJ, Stern GM. Challenge tests to predict the dopaminergic response in untreated Parkinson's disease. Neurology 1991;41:1723-1725.

41. Albin RL, Young AB, Penney JB. The functional anatomy of basal ganglia disorders. Trends Neurosci 1989;12:366-375.

42. DeLong MR. Primate models of movement disorders of basal ganglia origin. Trends Neurosci 1990;13:281-285.

43. Mengual E, de las Heras S, Erro E, Lanciego JL, Giménez-Amaya JM. Thalamic interaction between the input and the output systems of the basal ganglia. J Chem Neuroanat 1999;16:187-200.

44. Hammond C, Rouzaire-Dubois B, Féger J, Jackson A, Crossman AR. Anatomical and electrophysiological studies on the reciprocal projections between the subthalamic nucleus and nucleus tegmenti pedunculopontinus in the rat. Neuroscience 1983;9:41-52.

45. Kopell BH, Rezai AR, Chang JW, Vitek JL. Anatomy and physiology of the basal ganglia: implications for deep brain stimula- 
tion for Parkinson's disease. Mov Disord 2006;21 Suppl 14: S238-S246.

46. Urbain N, Rentéro N, Gervasoni D, Renaud B, Chouvet G. The switch of subthalamic neurons from an irregular to a bursting pattern does not solely depend on their GABAergic inputs in the anesthetic-free rat. J Neurosci 2002;22:8665-8675.

47. Wichmann T, Bergman H, DeLong MR. The primate subthalamic nucleus: III, Changes in motor behavior and neuronal activity in the internal pallidum induced by subthalamic inactivation in the MPTP model of parkinsonism. J Neurophysiol 1994;72:521-530.

48. Vitek JL. Mechanisms of deep brain stimulation: excitation or inhibition. Mov Disord 2002;17 Suppl 3:S69-S72.

49. Aziz TZ, Peggs D, Sambrook MA, Crossman AR. Lesion of the subthalamic nucleus for the alleviation of 1-methyl-4-phenyl1,2,3,6-tetrahydropyridine (MPTP)-induced parkinsonism in the primate. Mov Disord 1991;6:288-292.

50. Guridi J, Herrero MT, Luquin MR, et al. Subthalamotomy in parkinsonian monkeys: behavioural and biochemical analysis. Brain 1996;119:1717-1727.

51. Vidakovic A, Dragasevic N, Kostic VS. Hemiballism: report of 25 cases. J Neurol Neurosurg Psychiatry 1994;57:945-949.

52. Pollak P, Benabid AL, Gross C, et al. Effects of the stimulation of the subthalamic nucleus in Parkinson disease [In French]. Rev Neurol (Paris) 1993;149:175-176.

53. Kleiner-Fisman G, Herzog J, Fisman DN, et al. Subthalamic nucleus deep brain stimulation: summary and meta-analysis of outcomes. Mov Disord 2006;21 Suppl 14:S290-S304.

54. Hamani C, Richter E, Schwalb JM, Lozan AM. Bilateral subthalamic nucleus stimulation for Parkinson's disease: a systematic review of the clinical literature. Neurosurgery 2005;56:13131321; discussion 1321-1314.

55. Krack P, Batir A, Van Blercom N, et al. Five-year follow-up of bilateral stimulation of the subthalamic nucleus in advanced Parkinson's disease. N Engl J Med 2003;349:1925-1934.

56. Schüpbach WMM, Chastan N, Welter ML, et al. Stimulation of the subthalamic nucleus in Parkinson's disease: a 5 year follow up. J Neurol Neurosurg Psychiatry 2005;76:1640-1644.

57. Deuschl G, Schade-Brittinger C, Krack P, et al. A randomized trial of deep-brain stimulation for Parkinson's disease [Erratum in: N Engl J Med 2006;355:1289]. N Engl J Med 2006; 355:896-908.

58. Schüpbach WMM, Maltête D, Houeto JL, et al. Neurosurgery at an earlier stage of Parkinson disease: a randomized, controlled trial. Neurology 2007;68:267-271.

59. Derost PP, Ouchchane L, Morand D, et al. Is DBS-STN appropriate to treat severe Parkinson disease in an elderly population? Neurology 2007;68:1345-1355.

60. Limousin P, Pollak P, Hoffmann D, Benazzouz A, Perret JE, Benabid AL. Abnormal involuntary movements induced by subthalamic nucleus stimulation in parkinsonian patients. Mov Disord 1996;11:231-235.

61. Santens P, De Letter M, Van Borsel J, De Reuck J, Caemaert J. Lateralized effects of subthalamic nucleus stimulation on different aspects of speech in Parkinson's disease. Brain Lang 2003; 87:253-258.

62. Temel Y, Kessels A, Tan S, Topdag A, Boon P, Visser-Vandewalle $\mathrm{V}$. Behavioural changes after bilateral subthalamic stimulation in advanced Parkinson disease: a systematic review. Parkinsonism Relat Disord 2006;12:265-272.

63. Berney A, Vingerhoets F, Perrin A, et al. Effect on mood of subthalamic DBS for Parkinson's disease: a consecutive series of 24 patients. Neurology 2002;59:1427-1429.

64. Piasecki SD, Jefferson JW. Psychiatric complications of deep brain stimulation for Parkinson's disease. J Clin Psychiatry 2004; 65:845-849

65. Burkhard PR, Vingerhoets FJ, Berney A, Bogousslavsky J, Villemure JG, Ghika J. Suicide after successful deep brain stimulation for movement disorders. Neurology 2004;63:2170-2172.

66. Hutchison WD, Lozano AM, Tasker RR, Lang AE, Dostrovsky JO. Identification and characterization of neurons with tremorfrequency activity in human globus pallidus. Exp Brain Res 1997; 113:557-563.
67. Davis KD, Taub E, Houle S, et al. Globus pallidus stimulation activates the cortical motor system during alleviation of parkinsonian symptoms. Nat Med 1997;3:671-674.

68. Baron MS, Vitek JL, Bakay RA, et al. Treatment of advanced Parkinson's disease by posterior GPi pallidotomy: 1-year results of a pilot study. Ann Neurol 1996;40:355-366.

69. Lang AE, Lozano AM, Montgomery E, Duff J, Tasker R, Hutchinson W. Posteroventral medial pallidotomy in advanced Parkinson's disease. N Engl J Med 1997;337:1036-1042.

70. Laitinen LV, Bergenheim AT, Hariz MI. Ventroposterolateral pallidotomy can abolish all parkinsonian symptoms. Stereotact Funct Neurosurg 1992;58:14-21.

71. Gross C, Rougier A, Guehl D, Boraud T, Julien J, Bioulac B. High-frequency stimulation of the globus pallidus internalis in Parkinson's disease: a study of seven cases. J Neurosurg 1997; 87:491-498.

72. Pahwa R, Wilkinson S, Smith D, Lyons K, Miyawaki E, Koller WC. High-frequency stimulation of the globus pallidus for the treatment of Parkinson's disease. Neurology 1997;49:249-253.

73. Kumar R, Lang AE, Rodriguez-Oroz MC, et al. Deep brain stimulation of the globus pallidus pars interna in advanced Parkinson's disease. Neurology 2000;55:S34-S39.

74. Volkmann J, Allert N, Voges J, Sturm V, Schnitzler A, Freund HJ. Long-term results of bilateral pallidal stimulation in Parkinson's disease. Ann Neurol 2004;55:871-875.

75. Visser-Vandewalle V, van der Linden C, Temel Y, Nieman F, Celik H, Beuls E. Long-term motor effect of unilateral pallidal stimulation in 26 patients with advanced Parkinson disease. J Neurosurg 2003;99:701-707.

76. Vingerhoets G, van der Linden C, Lannoo E, et al. Cognitive outcome after unilateral pallidal stimulation in Parkinson's disease. J Neurol Neurosurg Psychiatry 1999;66:297-304.

77. Volkmann J, Allert N, Voges J, Weiss PH, Freund HJ, Sturm V. Safety and efficacy of pallidal or subthalamic nucleus stimulation in advanced PD [Erratum in: Neurology 2001;57:1354]. Neurology 2001;56:548-551.

78. Burchiel KJ, Anderson VC, Favre J, Hammerstad JP. Comparison of pallidal and subthalamic nucleus deep brain stimulation for advanced Parkinson's disease: results of a randomized, blinded pilot study. Neurosurgery 1999;45:1375-1382; discussion 1382-1374.

79. Peppe A, Pierantozzi M, Bassi A, et al. Stimulation of the subthalamic nucleus compared with the globus pallidus internus in patients with Parkinson disease. J Neurosurg 2004;101:195-200.

80. Rodriguez-Oroz MC, Obeso JA, Lang AE, et al. Bilateral deep brain stimulation in Parkinson's disease: a multicentre study with 4 years follow-up. Brain 2005;128:2240-2249.

81. Anderson VC, Burchiel KJ, Hogarth P, Favre J, Hammerstad JP. Pallidal vs subthalamic nucleus deep brain stimulation in Parkinson disease. Arch Neurol 2005;62:554-560.

82. Fahn S, Bressman SB, Marsden CD. Classification of dystonia. Adv Neurol 1998;78:1-10.

83. Krauss JK, Pohle T, Weber S, Ozdoba C, Burgunder JM. Bilateral stimulation of globus pallidus internus for treatment of cervical dystonia. Lancet 1999;354:837-838.

84. Ozelius LJ, Hewett J, Kramer P, et al. Fine localization of the torsion dystonia gene (DYT1) on human chromosome 9q34: YAC map and linkage disequilibrium. Genome Res 1997;7:483-494.

85. Ozelius LJ, Hewett JW, Page CE, et al. The early-onset torsion dystonia gene $(D Y T 1)$ encodes an ATP-binding protein. Nat Genet 1997;17:40-48.

86. Bressman SB, de Leon D, Raymond D, et al. Clinical-genetic spectrum of primary dystonia. Adv Neurol 1998;78:79-91.

87. Han F, Racacho L, Lang AE, Bulman DE, Grimes DA. Refinement of the DYT15 locus in myoclonus dystonia. Mov Disord 2007;22:888-892.

88. Grotzsch H, Pizzolato GP, Ghika J, et al. Neuropathology of a case of dopa-responsive dystonia associated with a new genetic locus, DYT14. Neurology 2002;58:1839-1842.

89. Valente EM, Bentivoglio AR, Cassetta E, et al. DYT13, a novel primary torsion dystonia locus, maps to chromosome $1 \mathrm{p} 36.13$ 36.32 in an Italian family with cranial-cervical or upper limb onset. Ann Neurol 2001;49:362-366. 
90. Fahn S. Drug treatment of hyperkinetic movement disorders. Semin Neurol 1987;7:192-208.

91. Jankovic J, Schwartz K. Response and immunoresistance to botulinum toxin injections. Neurology 1995;45:1743-1746.

92. Brin MF, Jankovic J, Comella C, et al. Treatment of cervical dystonia using botulinum toxin. In: Kurlan R, Treatment of movement disorders. Philadelphia: Lippincott Williams \& Wilkins, 1995:183-246.

93. Lew MF, Brashear A, Factor S. The safety and efficacy of botulinum toxin type B in the treatment of patients with cervical dystonia: summary of three controlled clinical trials. Neurology 2000;55:S29-S35.

94. Ondo WG, Krauss JK. Surgical therapies for dystonia. In: Brin MF, Comella C, Jankovic J, Dystonia: etiology, clinical features, and treatment. Philadelphia: Lippincott Williams \& Wilkins, 2003:125-147.

95. Cooper IS. 20-year followup study of the neurosurgical treatment of dystonia musculorum deformans. Adv Neurol 1976;14:423452.

96. Andrew J, Fowler CJ, Harrison MJ. Stereotaxic thalamotomy in 55 cases of dystonia. Brain 1983;106:981-1000.

97. Cardoso F, Jankovic J, Grossman RG, Hamilton WJ. Outcome after stereotactic thalamotomy for dystonia and hemiballismus. Neurosurgery 1995;36:501-507; discussion 507-508.

98. Tasker RR, Doorly T, Yamashiro K. Thalamotomy in generalized dystonia. Adv Neurol 1988;50:615-631.

99. Iacono RP, Kuniyoshi SM, Lonser RR, Maeda G, Inae AM, Ashwal S. Simultaneous bilateral pallidoansotomy for idiopathic dystonia musculorum deformans. Pediatr Neurol 1996;14:145148.

100. Vitek JL, Zhang J, Evatt M, et al. GPi pallidotomy for dystonia: clinical outcome and neuronal activity. Adv Neurol 1998;78:211219.

101. Lozano AM, Kumar R, Gross RE, et al. Globus pallidus internus pallidotomy for generalized dystonia. Mov Disord 1997;12:865870 .

102. Silberstein P, Kuhn AA, Kupsch A, et al. Patterning of globus pallidus local field potentials differs between Parkinson's disease and dystonia. Brain 2003;126:2597-2608.

103. Vitek JL, Chockkan V, Zhang JY, et al. Neuronal activity in the basal ganglia in patients with generalized dystonia and hemiballismus. Ann Neurol 1999;46:22-35.

104. Hutchison WD, Lang AE, Dostrovsky JO, Lozano AM. Pallidal neuronal activity: implications for models of dystonia. Ann Neurol 2003;53:480-488.

105. Lenz FA, Suarez JI, Metman LV, et al. Pallidal activity during dystonia: somatosensory reorganisation and changes with severity. J Neurol Neurosurg Psychiatry 1998;65:767-770.

106. Kuhn AA, Meyer BU, Trottenberg T, Brandt SA, Schneider GH, Kupsch A. Modulation of motor cortex excitability by pallidal stimulation in patients with severe dystonia. Neurology 2003;60: 768-774.

107. Magyar-Lehmann S, Antonini A, Roelcke U, et al. Cerebral glucose metabolism in patients with spasmodic torticollis. Mov Disord 1997; $12: 704-708$.

108. Kupsch A, Kuehn A, Klaffke S, et al. Deep brain stimulation in dystonia. J Neurol 2003;250 Suppl 1:I47-I52.

109. Yianni J, Bain PG, Gregory RP, et al. Post-operative progress of dystonia patients following globus pallidus internus deep brain stimulation. Eur J Neurol 2003;10:239-247.

110. Coubes P, Roubertie A, Vayssiere N, Hemm S, Echenne B. Treatment of DYT1-generalised dystonia by stimulation of the internal globus pallidus. Lancet 2000;355:2220-2221.
111. Cif L, El Fertit H, Vayssiere N, et al. Treatment of dystonic syndromes by chronic electrical stimulation of the internal globus pallidus. J Neurosurg Sci 2003;47:52-55.

112. Vidailhet M, Vercueil L, Houeto JL, et al. Bilateral deep-brain stimulation of the globus pallidus in primary generalized dystonia. N Engl J Med 2005;352:459-467.

113. Kupsch A, Benecke R, Muller J, et al. Pallidal deep-brain stimulation in primary generalized or segmental dystonia. N Engl J Med 2006;355:1978-1990.

114. Capelle HH, Weigel R, Krauss JK. Bilateral pallidal stimulation for blepharospasm-oromandibular dystonia (Meige syndrome). Neurology 2003;60:2017-2018.

115. Muta D, Goto S, Nishikawa S, et al. Bilateral pallidal stimulation for idiopathic segmental axial dystonia advanced from Meige syndrome refractory to bilateral thalamotomy. Mov Disord 2001; 16:774-777.

116. Holloway KL, Baron MS, Brown R, Cifu DX, Carne W, Ramakrishnan V. Deep brain stimulation for dystonia: a meta-analysis. Neuromodulation 2006;9:253-261.

117. Kupsch A, Klaffke S, Kühn AA, et al. The effects of frequency in pallidal deep brain stimulation for primary dystonia [Erratum in: J Neurol 2004;251:1031]. J Neurol 2003;250:1201-1205.

118. Alterman RL, Shils JL, Miravite J, Tagliati M. Lower stimulation frequency can enhance tolerability and efficacy of pallidal deep brain stimulation for dystonia. Mov Disord 2007;22:366-368.

119. Kelly PJ, Derome P, Guiot G. Thalamic spatial variability and the surgical results of lesions placed with neurophysiologic control. Surg Neurol 1978;9:307-315.

120. Andrade-Souza YM, Schwalb JM, Hamani C, et al. Comparison of three methods of targeting the subthalamic nucleus for chronic stimulation in Parkinson's disease. Neurosurgery 2005;56(2 Suppl):360-368; discussion 360-368.

121. Nowinski WL, Belov D, Pollak P, Benabid AL. Statistical analysis of 168 bilateral subthalamic nucleus implantations by means of the probabilistic functional atlas. Neurosurgery 2005;57:319330; discussion 319-330.

122. D'Haese PF, Pallavaram S, Niermann K, et al. Automatic selection of DBS target points using multiple electrophysiological atlases. Med Image Comput Comput Assist Interv Int Conf Med Image Comput Comput Assist Interv 2005;8:427-434.

123. Umemura A, Jaggi JL, Hurtig HI, et al. Deep brain stimulation for movement disorders: morbidity and mortality in 109 patients. J Neurosurg 2003;98:779-784.

124. Henderson JM. Frameless localization for functional neurosurgical procedures: a preliminary accuracy study. Stereotact Funct Neurosurg 2004;82:135-141.

125. Fitzpatrick JM, Konrad PE, Nickele C, Cetinkaya E, Kao C. Accuracy of customized miniature stereotactic platforms. Stereotact Funct Neurosurg 2005;83:25-31.

126. Lenz FA, Dostrovsky JO, Kwan HC, Tasker RR, Yamashiro K, Murphy JT. Methods for microstimulation and recording of single neurons and evoked potentials in the human central nervous system. J Neurosurg 1988;68:630-634.

127. Hariz MI, Fodstad H. Do microelectrode techniques increase accuracy or decrease risks in pallidotomy and deep brain stimulation? A critical review of the literature. Stereotact Funct Neurosurg 1999;72:157-169.

128. Binder DK, Rau GM, Starr PA. Risk factors for hemorrhage during microelectrode-guided deep brain stimulator implantation for movement disorders. Neurosurgery 2005;56:722-732; discussion $722-732$.

129. Yamamoto M, Jimbo M, Ide M, Tanaka N, Umebara Y, Hagiwara S. Postoperative neurosurgical infection and antibiotic prophylaxis. Neurol Med Chir (Tokyo) 1992;32:72-79. 